\title{
Meaningful Living to Promote Complete Mental Health Among University Students in the Context of the COVID-19 Pandemic
}

\author{
Gökmen Arslan $^{1,2}$ (D) $\cdot$ Murat Yıldırım $^{3,4} \cdot$ Zeynep Karataş $^{5} \cdot$ Zekavet Kabasakal $^{6}$ • \\ Mustafa Kılınç5
}

Accepted: 16 October 2020 / Published online: 3 November 2020

(C) Springer Science+Business Media, LLC, part of Springer Nature 2020

\begin{abstract}
Maintaining positive mental health can be challenging during the COVID-19 pandemic which undoubtedly caused devastating consequences on people's lives. There is need to determine factors contributing to mental health of people during the pandemic. The current study aims to examine the effect of meaning in life on complete mental health, which represents the presence of positive functioning and the absence of psychopathological symptoms. The participants of the study included 392 (70.9\% female) undergraduate students, ranging in age from 18 to 43 years $(M=20.67$ years, $S D=3.66)$ and they have predominantly been imposed stay-at-home orders for coronavirus right after announcement of COVID-19 restrictions in Turkey. Latent variable path analyses demonstrated significant paths from meaning in life to all components of psychological distress, positive mental health, and subjective well-being. Multi-group analysis showed significant gender differences across the study variables. These findings corroborate the critical role of meaning in life in promoting complete mental health and shed further light on why people high in meaning in life tend to have better mental health than those low in meaning in life within the context of COVID-19.
\end{abstract}

Keywords Meaning in life $\cdot$ Complete mental health $\cdot$ Psychological distress $\cdot$ Psychological wellbeing $\cdot$ Subjective well-being

Gökmen Arslan

gkmnarslan@gmail.com

1 Burdur Mehmet Akif Ersoy University, Burdur, Turkey

2 International Network on Personal Meaning, Toronto, Ontario, Canada

3 Ağrı İbrahim Çeçen University, Ağri, Turkey

4 University of Leicester, Leicester, UK

5 Faculty of Education, Mehmet Akif Ersoy University, Burdur, Turkey

6 Dokuz Eylül University, Konak, Turkey 
The COVID-19 outbreak initially started in December 2019 in China and spread rapidly to other countries by affecting almost all aspects of human life such as health, social, education, and economy (Tanhan 2020; Tanhan et al. 2020). According to daily statistics published by the Johns Hopkins University, as of 2 October 2020, there have been more than 34 million people confirmed with COVID-19 globally and more than 1 million deaths touching 188 countries and territories (Center for Systems Science and Engineering 2020). In Turkey, many measures were put in place to control the COVID-19 through the closure of borders, the restriction of travel, public gatherings, and spending time outside of the home. While hospitals managed unprecedented pressure on the healthcare system, the country experienced the loss of lives, economic stress, job losses, illness, and social isolation spurred on by quarantine measures (Arslan 2020a; Yıldırım and Arslan 2020; Yıldırım and Güler 2020a). As of 02 October 2020, there were more than 321,500 people confirmed with COVID-19, and 8300 deaths (Center for Systems Science and Engineering 2020).

Studies reported that measures taken to control the COVID-19 pandemic (e.g., quarantine) have significant effects on individuals both in short-term and long-term such as experience of fears of infection, frustration, and boredom (Tian et al. 2020). Similar to previous research on infectious diseases like MERS where high levels of mental health problems (e.g., anxiety, aggression) were reported (Jeong et al. 2016), recent evidence on COVID-19 demonstrated that people suffer from a wide range of mental health problems including panic attacks, anxiety, and depression (Ahorsu et al. 2020; Qiu et al. 2020). However, psychological strengths like meaningful living, resilience, and hope were found to significantly promote mental health during the pandemic (Yıldırım and Arslan 2020; Arslan et al. 2020).

Individuals' perception of meaning in life has become one of the main study areas with emergence of positive psychology. Meaning in life is as a subjective concept that includes several key components such as success, love, and inevitable suffering (Frankl 1985). The concept of meaning in life constitutes the basic motivation source of individual in an existential approach (Sharf 2012). Search for meaning in life is one of the fundamental psychological needs of human being. According to Frankl (1985), people differ in their levels of meaning in life. In times of difficulties, those who have meaning and purpose in life can survive much longer than those who lack in meaningful living. Despite the wide variety of stressors that people can experience in the face of adversities such as the current pandemic, they can still function positively by turning into their own essence of finding meaning in life. Many studies have supported the importance of meaning in life to various mental health indicators such as social and physical functioning, subjective well-being, psychological well-being hope, depression, social support, and anxiety (Jim and Andersen 2007; Kleftaras and Psarra 2012; Lin 2020; Mascaro and Rosen 2005; Minkkinen et al. 2020; Zika and Chamberlain 1992; Wang et al. 2006). Although limited, meaning in life was also found to be related with emotional well-being (Garrosa-Hernández et al. 2013). Meaninglessness can cause psychopathology and psychological disorders (Maccallum and Bryant 2019). It has also been found to act as a protective factor against intrusive thoughts and psychological distress among breast cancer survivors who need to adjust to new situations (Vickberg et al. 2000). These results suggest that meaning in life is a critical ingredient of human functioning.

Complete mental health refers to the presence of positive functioning and the absence of psychopathological symptoms (Arslan and Allen 2020). Complete mental health consists of both mental well-being and ill-being. Mental ill-health embodies a wide variety of difficulties experienced by people such as depression, anxiety, stress, worries, loneliness, and adjustment problems that diminishes optimal functioning (Allen and McKenzie 2015; Arslan and Allen 
2020; Spiker and Hammer 2019; Tanhan 2019). Mental well-being, on the other hand, includes the presence of fulfillment with emotional, social, and psychological experiences (Keyes 2014; Seligman and Csikszentmihalyi 2000; Smith et al. 2020). The absence of mental illness does not completely reflect the presence of well-being or vice versa (Keyes 2014). Researchers suggested the continuity of mental health to describe one's fully functioning in social, emotional, and psychological domains (Diener et al. 1999; Keyes 2014). A complete mental health can be achieved by considering both positive and negative states of mind and body. Thus, as there are differentiated conceptualization of well-being, researchers have suggested to simultaneously measure different types of well-being (e.g., subjective and psychological well-being) and mental illnesses (e.g., depression and anxiety) to comprehensively understand mental health (Ryan and Deci 2001). Complete mental health is linked to coping, self-esteem, optimism, psychological flexibility, feeling of control, resilience, functioning, and adjustment (Arslan 2018; Arslan and Allen 2020; Bieda et al. 2017; Keyes 2002; Keyes 2005; Moore and Diener 2019; Peterson and Seligman 2004).

Well-being typically refers to "optimal psychological functioning and experience" and is a multidimensional construct including hedonic and eudaimonic dimensions (Ryan and Deci 2001). Hedonic well-being typically reflects subjective well-being (SWB) that incorporates satisfaction with life, positive affect, and negative affect while eudaimonic well-being is conceptualized as positive skills that promote living a life of virtue in pursuit of human excellence. Eudaimonic well-being is best represented with psychological well-being (PWB) that includes six dimensions of optimal functioning: purpose in life, environmental mastery, autonomy, personal growth, positive relations, and self-acceptance (Ryff and Keyes 1995; Ryff et al. 1999). Although SWB and PWB are conceptually overlap to some extent, they are empirically distinct concepts (Ryan and Deci 2001). Research has shown that both SWB and PWB are associated with psychosocial and physical outcomes. For example, in a systematic review study, Lyubomirsky et al. (2005) documented that there are various tangible benefits of well-being such as better general health, effective coping strategies, fulfilling social relationships, and success. More recently, similar findings have been reported concerning the link between well-being and health outcomes (Gruber and Bekoff 2017; Huang and Humphreys 2012; Kansky and Diener 2017), and self-productivity, success, subjective vitality, meaning, self-esteem, and marital satisfaction (Akdağ and Cihangir-çankaya 2015; Braaten et al. 2019).

Given that the perception of meaning in life and mental health of individual may be adversely affected during difficult times like the COVID-19 pandemic, it is necessary to understand the link between meaning in life and complete mental health in such times. Therefore, the main purpose of this study is to examine the association between meaning in life, psychological health problems, positive mental health, and subjective well-being. We hypothesized that meaning in life would be a significant predictor of all indicators of complete mental health and the predictive effect of meaning in life on indicators of complete mental health would differ across female and male participants.

\section{Method}

\section{Participants}

The participants included 392 (70.9\% female and 29.1\% male) undergraduate students attending a public university in an urban city of Turkey. They ranged in age from 18 to 
43 years $(M=20.67$ years, $S D=3.66)$. The unique characteristic of the participants is that $68 \%$ of them were under 20 years old who have been imposed stay-at-home orders for coronavirus right after announcement of COVID-19 restrictions. Most of them considered themselves at medium-risk for coronavirus (low $=31.3 \%$; medium $=60.9 \%$; high $=7.7 \%$ ). All participants were informed about the aims of study and their rights to withdraw at any time from the online survey. A convenience sampling method was used to collect data. Participants were not paid for their involvement.

\section{Measures}

Meaning in Life Meaningful Living Measure (MLM) was used to assess the meaning in life with a 6-item self-report measure that is scored based on a 7-point Likert-type scale from strongly disagree (1) to strongly agree (7) (e.g., "As a whole, I find my life meaningful"). Previous research has revealed that the MLM provided good data-model fit and strong internal reliability estimates with Turkish adults (Arslan 2020b). The scale had also a strong internal reliability estimate with the current sample $(\alpha=.82)$.

Psychological Distress Brief Symptom Inventory (BSI-18) was used to measure mental health difficulties of individuals (Derogatis and Fitzpatrick 2004). The scale is an 18-item self-report questionnaire and includes three 6-item subscales: depression, anxiety, and somatization (e.g., "Pains in heart or chest," "Feeling no interest in things"). All items are responded using a 5-point Likert-type scale, ranging from not at all (0) to very much (4). Although psychometrics of the previous versions (SCL-90 and BSI-53) of the scale have been examined with Turkish samples, psychometric properties of current version are still not available. Therefore, the psychometric adequacy of the BSI-18 was investigated using the sample of this study. Confirmatory factor analysis results, which structured the 18 observed BSI items as indicators of three subscales, indicated that the measurement model yielded adequate datamodel fit statistics $\left(\chi^{2}=414.99, d f=130, p<.001\right.$, TLI $=.90, \mathrm{CFI}=.92$, RMSEA $[90 \% \mathrm{CI}]=$ .075 ). Factor loadings of the scale were strong ranging from .49 to .85 (somatization $\lambda$ range $=.57-.74$; depression $\lambda$ range $=.49-.85$; anxiety $\lambda$ range $=.50-.79$; covariance $=3-11$ items and 16-17 items), and internal reliability coefficients (overall BSI-18 $\alpha=.93$; somatization $\alpha=.84$; depression $\alpha=.83$; anxiety $\alpha=.86$ ). These results provided good evidence for a three-factor model of the BSI-18 that could be used to measure psychological distress among young adults.

Positive Mental Health Mental Health Continuum Short Form (MHC-SF) is a 14-item selfreport measure developed to assess individuals' social, emotional, and psychological wellbeing representing the level of positive mental health (e.g. "In the past month, how often did you feel that our society is becoming a better place for people?"; Keyes et al. 2008). All items are scored using a 6-point Likert scale, ranging between never (0) and almost (5). Previous research has provided evidence supporting good psychometric properties in different cultures (Keyes et al. 2008; Petrillo et al. 2015) including Turkish culture (Demirci and Ahmet 2015). The scales had also strong internal reliability estimate with the present sample ( $\alpha$ range $=$ .83-.88, see Table 1).

Subjective Well-being The Scale of Positive and Negative Experience (SPANE) (Diener et al. 2010) and the Satisfaction with Life Scale (SWLS) (Diener et al. 1985) were combined to 
Table 1 Descriptive statistics and correlations

\begin{tabular}{|c|c|c|c|c|c|}
\hline Scales & Mean & Std. deviation & Skewness & Kurtosis & $\alpha$ \\
\hline Meaning in life & 34.20 & 5.75 & -1.52 & 3.43 & .82 \\
\hline \multicolumn{6}{|l|}{ Subjective well-being } \\
\hline Life satisfaction & 21.25 & 6.12 & -.28 & -.42 & .85 \\
\hline Positive affect & 20.40 & 4.36 & -.36 & .09 & .90 \\
\hline Negative affect & 15.99 & 3.61 & -.15 & .04 & .77 \\
\hline \multicolumn{6}{|l|}{ Positive mental health } \\
\hline Emotional well-being & 9.62 & 2.94 & -.55 & .34 & .83 \\
\hline Social well-being & 14.02 & 5.08 & -.25 & -.13 & .86 \\
\hline Psychological well-being & 21.86 & 5.80 & -1.10 & 1.47 & .88 \\
\hline \multicolumn{6}{|l|}{ Psychological distress } \\
\hline Somatization & 5.19 & 4.76 & 1.11 & .92 & .84 \\
\hline Depression & 8.04 & 5.47 & .54 & -.39 & .83 \\
\hline Anxiety & 6.49 & 4.64 & .94 & .54 & .86 \\
\hline
\end{tabular}

measure individuals' subjective well-being. The SPANE is a 12-item self-report questionnaire used to assess individuals' emotions and moods and includes two 6-item subscales: positive feeling experience (e.g., "Pleasant," "Good") and negative feeling experience (e.g., "Unpleasant," "Negative"). All items are rated on a 5-point Likert scale, ranging from very rarely or never (1) to very often or always (5). Research indicated that the scale had good psychometric properties and strong internal reliability estimates for Turkish samples (Telef 2013). The SWLS was also used to assess individuals' cognitive assessments of well-being. The scale is a 5-item self-report instrument (e.g., "The conditions of my life are excellent") that is answered using a 7-point Likert-type scale, ranging from strongly agree (7) to strongly disagree (1). Previous research showed that the reliability coefficients of the SWLS were adequate for Turkish sample (Dağlı and Baysal 2016). The internal reliability estimate of the scale was strong in the present study ( $\alpha$ range $=.77-.90$, see Table 1 ).

\section{Data Analysis}

Prior to examining the predictive power of the meaning in life on complete mental health indicators, descriptive statistics and the assumption of normal distribution were investigated. Following excluding the messing scores (6 participants), skewness and kurtosis scores were used to investigate the normality assumption, and the estimates $\leq|3|$ were considered as adequate for normality (D'Agostino et al. 1990; Kline 2015). Then, Pearson's correlation analysis was conducted to examine the association between the study variables. Subsequently, a pair of latent variable path analysis (LVPA) was conducted to examine the predictive effect of the MLM on student's complete mental health identified by positive mental health, psychological distress, and subjective well-being indicators. Findings from path analyses were interpreted using the standardized regression estimates ( $\beta$ values) and squared-multiple correlations $\left(R^{2}\right)$, with traditional decision rules: $.01-.059=$ small, $.06-.139=$ moderate, $\geq .14=$ large $($ Cohen 1988). Findings from this analysis were also evaluated using several data-model fit statistics and their cut-scores: comparative fit index (CFI) and Tucker Lewis index (TLI) values $\geq .90$ were considered an adequate data-model fit; the root mean square error of approximation (RMSEA; with 90\% CI) values between .05 and .08 were viewed as a good data-model fit (Hooper et al. 2008; Hu and Bentler 1999). Furthermore, multi-group analysis was conducted to investigate gender differences on the study variables. All statistical analyses were performed using SPSS version 25 and AMOS version 24. 


\section{Results}

Findings from descriptive analysis showed that skewness and kurtosis scores ranged between -1.52 and 3.43, suggesting that all variables provided relatively normal distribution (D'Agostino et al. 1990; Kline 2015). Internal reliability estimates of the study variables were adequate-to-strong, ranging from .77 to .90 , as shown in Table 1. Further, correlation analysis was performed to investigate the association between variables, indicating that meaning in life was positively and significantly correlated with life satisfaction $(r=.58, p<.001)$, positive feelings $(r=.42, p<.001)$, and emotional $(r=.46, p<.001)$, social $(r=.50, p<.001)$, and psychological well-being $(r=.61, p<.001)$, ranging from moderate to large effect sizes. Meaning in life had also significant and negative correlations with negative feelings $(r=-.23, p<.001)$, somatization $(r=-.30, p<.001)$, depression $(r=-.47, p<.001)$, and anxiety $(r=-.32, p<.001)$, ranging from small to large effect sizes, as shown in Table 2.

Following conducting the descriptive and correlation analyses, the LVPA was performed to investigate the predictive effect of the measurement model on student mental health and wellbeing. Overall, results of this analysis provided good data-model fit statistics $\left(\chi^{2}=153.39, d f=\right.$ $54, p<.001$, RMSEA = .069 [90\% CI .58-.82], CFI = 97, and TLI = .93). Standardized regression estimates indicated that meaning in life significantly and moderately-to-largely predicted subjective well-being components, ranging from .06 to 41 effect sizes: life satisfaction ( $\beta=.64$, $t=11.80, p<.001)$, positive feeling $(\beta=.45, t=8.20, p<.001)$, and negative feelings $(\beta=$ $-.24, t=-4.28, p<.001)$. Subsequently, meaning in life had significant and strong predictive effects on positive mental health indicators, ranging from .25 to 44 effect sizes: emotional $(\beta=.50, t=9.18, p<.001)$, social $(\beta=54, t=9.82, p<.001)$, and psychological well-being $(\beta=66, t=12.21, p<.001)$. Lastly, findings of the study indicated the significant and large predictive effects of meaning in life on student psychological difficulties, ranging from .11 to 26 effect sizes: somatization $(\beta=-.33, t=-5.95, p<.001)$, depression $(\beta=-.51, t=-9.40$, $p<.001)$, and anxiety $(\beta=-.35, t=-6.41, p<.001)$, see Table 1 and Fig. 1 .

Multi-group analysis was also performed to investigate the differences between male and female students. Findings from the analysis showed that the model yielded good data-model fit statistics $\left(\chi^{2}=264.72, d f=108, p<.001\right.$, RMSEA $=.061$ [90\% CI .52-.70], CFI $=95$, and $\mathrm{TLI}=.90)$. Standardized regression estimates showed that meaning in life had a strong

Table 2 Correlations between the study variables

\begin{tabular}{|c|c|c|c|c|c|c|c|c|c|c|}
\hline Scales & 1. & 2. & 3. & 4. & 5. & 6. & 7. & 8. & 9. & 10. \\
\hline 1. Meaning in life & 1 & $.58 * *$ & $.42 * *$ & $-.23 * *$ & $.46^{* *}$ & $.50 * *$ & $.61 * *$ & $-.30 * *$ & $-.47 * *$ & $-.32 * *$ \\
\hline 2. Life satisfaction & & 1 & $.45^{* *}$ & $-.29 * *$ & $.58 * *$ & $.56^{* *}$ & $.55^{* *}$ & $-.33 * *$ & $-.54 * *$ & $-.34 * *$ \\
\hline 3. Positive affect & & & 1 & $-.36^{* *}$ & $.61 * *$ & $.48 * *$ & $.56^{* *}$ & $-.23 * *$ & $-.44 * *$ & $-.31 * *$ \\
\hline 4. Negative affect & & & & 1 & $-.28 * *$ & $-.23 * *$ & $-.34 * *$ & $.31 * *$ & $.44 * *$ & $.46 * *$ \\
\hline 5. Emotional well-being & & & & & 1 & $.69 * *$ & $.68 * *$ & $-.25 * *$ & $-.51 * *$ & $-.33 * *$ \\
\hline 6. Social well-being & & & & & & 1 & $.70 * *$ & $-.27 * *$ & $-.48 * *$ & $-.32 * *$ \\
\hline $\begin{array}{l}\text { 7. Psychological } \\
\text { well-being }\end{array}$ & & & & & & & 1 & $-.26^{* *}$ & $-.52 * *$ & $-.36^{* *}$ \\
\hline 8. Somatization & & & & & & & & 1 & $.61 * *$ & $.70 * *$ \\
\hline 9. Depression & & & & & & & & & 1 & $.75 * *$ \\
\hline 10. Anxiety & & & & & & & & & & 1 \\
\hline
\end{tabular}

$* * p<.001$ 


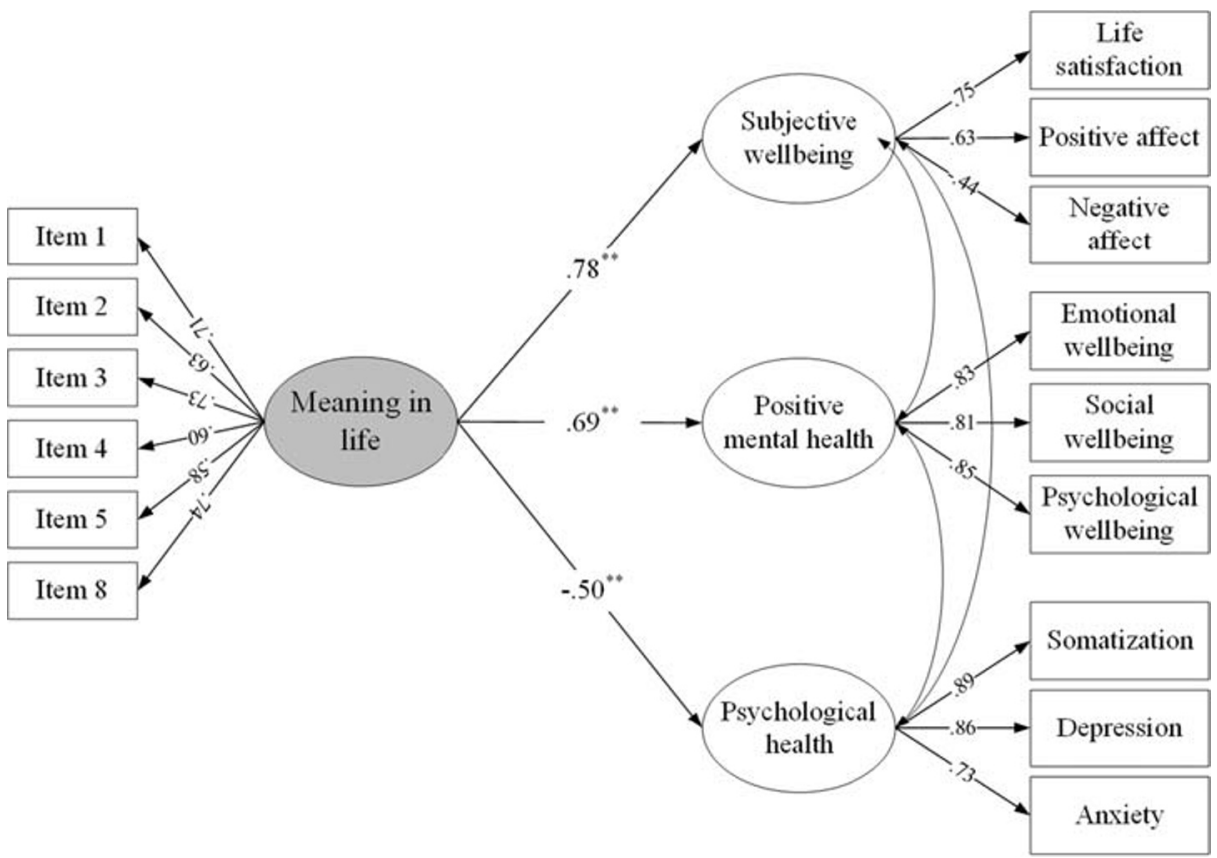

Fig. 1 The predictive effect of meaning in life on complete mental health indicators. Note. $* * p<.001$

predictive effect on psychological distress and positive mental health components in male students, compared with female students, as shown in Table 3. This evidence suggests that the predictive effect of meaning in life differs across female and male students; thus, caution may be warranted in comparing these groups.

Table 3 Standardized direct effects

\begin{tabular}{|c|c|c|c|c|c|c|c|c|}
\hline \multirow[t]{3}{*}{ Outcomes } & \multicolumn{8}{|c|}{ Meaning in life } \\
\hline & \multicolumn{4}{|c|}{ Total sample (BC 95\% CI) } & \multicolumn{2}{|l|}{ Female } & \multicolumn{2}{|l|}{ Male } \\
\hline & $\beta$ & $R^{2}$ & Lower & Upper & $\beta$ & $R^{2}$ & $\beta$ & $R^{2}$ \\
\hline \multicolumn{9}{|l|}{ Subjective well-being } \\
\hline Life satisfaction & $.64 * *$ & .41 & .53 & .73 & $.64 * *$ & .41 & $.63 * *$ & .39 \\
\hline Positive affect & $.45^{* *}$ & .20 & .32 & .56 & $.46^{* *}$ & .21 & $.43 * *$ & .18 \\
\hline Negative affect & $-.24 * *$ & .06 & -.34 & -.11 & $-.24 * *$ & .06 & $-.26 * *$ & .07 \\
\hline \multicolumn{9}{|l|}{ Positive mental health } \\
\hline Emotional well-being & $.50 * *$ & .25 & .35 & .63 & $.46^{* *}$ & .24 & $.58 * *$ & .33 \\
\hline Social well-being & $.54 * *$ & .29 & .42 & .64 & $.48 * *$ & .23 & $.66 * *$ & .44 \\
\hline Psychological well-being & $.66^{* *}$ & .44 & .52 & .77 & $.63 * *$ & .40 & $.72 * *$ & .52 \\
\hline \multicolumn{9}{|l|}{ Psychological distress } \\
\hline Somatization & $-.33 * *$ & .11 & -.44 & -.21 & $-.31 * *$ & .10 & $-.41 * *$ & .17 \\
\hline Depression & $-.51 * *$ & 26 & -.63 & -.37 & $-.47 * *$ & .22 & $-.61 * *$ & .37 \\
\hline Anxiety & $-.35 * *$ & .12 & -.46 & -.23 & $-.32 * *$ & .10 & $-.48 * *$ & .23 \\
\hline
\end{tabular}

$* * p<.001$, BC $95 \%$ CI for standardized direct effects = bootstrapped bias-corrected and accelerated confidence interval with sample 5000 


\section{Discussion}

The COVID-19 epidemic becomes the most challenging global health crisis in the twenty-first century. Although countries take necessary measures such as quarantine and self-isolation to decelerate, COVID-19 is much more than a health crisis. It has the potential to create devastating psychological, social, economic, and political crises that will leave deep wounds as it has been continuing to affect many societies unprecedentedly. This can be a severe source of stress and anxiety for everyone. Therefore, it is crucial for the individual to cope with stressors, adjust to the changes in general lifestyle due to COVID-19, and maintain their mental health. (Rosenberg 2020). Meaning in life is one of the most important components of coping with stressors in difficult times. It is very important to develop an existential source of flexibility such as sense of meaning and purpose in this difficult process (Kim et al. 2005).

The present study sought to examine the role of meaning in life in enhancing the mental health and well-being of undergraduate students during the COVID-19 outbreak. We hypothesized that meaning in life would be a significant predictor of all indicators of complete mental health. The study results revealed that meaning in life negatively and significantly predicted negative effect and positively and significantly predicted positive affect and life satisfaction. Similar to the findings of the present study, previous studies revealed that meaning in life was positively associated with positive affectivity and life satisfaction while negatively related to negative affectivity, which are essential components of subjective well-being (Doğan et al. 2012; Galang et al. 2011; Santos et al. 2012; Y1ldırım and Güler 2020b). Arslan and Allen (2020) reported that meaning in life was a significant predictor of life satisfaction and mediated the negative effect of coronavirus stress on well-being. Santos et al. (2012) found that meaning in life was positively related to positive emotion and life satisfaction and negatively associated with negative emotions. Cohen and Cairns (2011) found a negative and significant correlation between searching for meaning in life and subjective well-being and a positive and significant correlation between the presence of meaning in life and subjective well-being.

Findings of the study additionally showed that meaning in life positively and significantly predicted positive mental health including emotional well-being, social well-being, and psychological well-being. This study has supported previous findings indicating that individuals with high level of the sense of meaning in life have grater emotional, psychological, and social well-being (Damasio et al. 2013; García-Alandete 2015; García-Alandete et al. 2018; Mulders 2011). Meaning in life significantly predicted psychological well-being (García-Alandete 2015; García-Alandete et al. 2018). Despite the literature supporting the importance of meaning in life to improve positive mental health, specifically psychological well-being, few studies have focused on the predictive effect of meaning in life on emotional and social well-being (Garrosa-Hernández et al. 2013). Therefore, the present study provides further evidence indicating that meaning in life is an important factor to promote not only psychological well-being but also emotional and social well-being.

Lastly, the results indicated that meaning in life had a negative and significant predictive effect on psychological health problems (i.e., depression, anxiety, and somatization), which are negative indicators of complete mental health. Consistent with these results, the literature has indicated that the sense of meaningful living is the key to better psychological health (Kleftaras and Psarra 2012; Mascaro and Rosen 2005, 2008; Steger et al. 2009). For example, Hedayati and Khazaei (2014) found a negative correlation between meaning in life and depressive symptoms. Another study indicated that there was a significant and negative correlation between meaning in life and anxiety, somatic symptoms, social dysfunction, and depressive symptoms. Individuals with depressive symptoms reported lower levels of meaning in life compared with those without (Kleftaras and Psarra 2012). 


\section{Implication and Limitations}

The current study focused on meaning in life, subjective well-being, and some indicators of positive mental health (emotional well-being, social well-being, and psychological well-being) and of negative mental health (depression, anxiety, and somatization). Future research may investigate the relationships of meaning in life with different variables. As negative correlations were found between meaning in life and depression, anxiety, and somatization in the current study, psychoeducational activities can be conducted with university students to nurture their meaning in life. Also, activities can be organized to increase the subjective well-being of university students so that their search for meaning in life can be supported. In the current study, significant correlations were found between meaning in life, social, emotional, and psychological well-being. In this regard, organization of activities to improve the psychological well-being of university students can contribute to their search for meaning in life.

The current study has several limitations that need to be taken into account when interpreting these results. Firstly, participants were self-selected students studying at a state university, thereby may not be a better representative of the general population. Due to the nature of COVID-19 which imposes people to physically and socially distance from one another (Ylldırm et al. 2020), we collected data using an online survey. However, limitations exist in Internet data collection as it only encompasses Internet users. Next, though using various self-report measures of mental health, wellbeing, and meaning in life was fruitful in obtaining a broader picture of complete mental health, there may be some factors affecting the reliability of current findings such as social desirability. Future research should use methods that reduce self-report recall biases. Additionally, this study was performed using a cross-sectional design, and longitudinal research could therefore offer additional insights into the associations between the variables. Finally, these findings should be iterated in more countries and cultures, with diverse samples as people may have different views of meaning in life and well-being.

In conclusion, the results suggest that meaning in life can explain increases in positive mental health and decreases in negative mental health. Meaning-centered intervention programs can be utilized in future research and practice to make changes in one's lives and promote their complete psychological functioning.

\section{Compliance with Ethical Standards}

Conflict of Interest The authors declare that they have no conflicts of interest.

Ethical Approval All procedures performed in studies involving human participants were in accordance with the ethical standards of the institutional and/or national research committee and with the 1964 Helsinki declaration and its later amendments or comparable ethical standards.

Informed Consent Consent was obtained from all participants included in the study.

\section{References}

Ahorsu, D. K., Lin, C. Y., Imani, V., Saffari, M., Griffiths, M. D., \& Pakpour, A. H. (2020). The Fear of COVID19 Scale: development and initial validation. International Journal of Mental Health and Addiction. Advance online publication. https://doi.org/10.1007/s11469-020-00270-8. 
Akdağ, F. G., \& Cihangir-çankaya, Z. (2015). Evli bireylerde psikolojik iyi oluşun yordanması. Mersin University Journal of the Faculty of Education, 11(3), 646-662.

Allen, K. A., \& McKenzie, V. L. (2015). Adolescent mental health in an Australian context and future interventions. International Journal of Mental Health, 44(1-2), 80-93. https://doi.org/10.1080 /00207411.2015.1009780.

Arslan, G. (2018). Exploring the association between school belonging and emotional health among adolescents. International Journal of Educational Psychology, 7(1), 11-21. https://doi.org/10.17583/ijep.2018.3117.

Arslan, G. (2020a). Loneliness, college belongingness, subjective vitality, and psychological adjustment during coronavirus pandemic: Development of the College Belongingness Questionnaire. Journal of Positive School Psychology. Retrieved from https://journalppw.com/index.php/JPPW/article/view/240.

Arslan, G. (2020b). Anlamlı Yașam Ölçeğinin geliștirilmesi: Anlamlı yașama ilișkin kısa ve etkili bir ölçme aracı [Development of the Meaningful Living Measure: A brief and effective measure of meaningful living]. Mehmet Akif Ersoy University. Journal of Education Faculty, 56, 227-242. https://doi.org/10.21764 /maeuefd.773686.

Arslan, G., \& Allen, K. A. (2020). Complete mental health in elementary school children: understanding youth school functioning and adjustment. Current Psychology. Advance online publication. https://doi. org/10.1007/s12144-020-00628-0.

Arslan, G., Yıldırım, M., \& Wong, P. T. P. (2020). Meaningful living, resilience, affective balance, and psychological health problems among Turkish young adults. PsyArXiv. https://doi.org/10.31234/osf. io/wsr3e.

Bieda, A., Hirschfeld, G., Schönfeld, P., Brailovskaia, J., Zhang, X. C., \& Margraf, J. (2017). Universal happiness? Cross-cultural measurement invariance of scales assessing positive mental health. Psychological Assessment, 29(4), 1-12. https://doi.org/10.1037/pas0000353.

Braaten, A., Huta, V., Tyrany, L., \& Thompson, A. (2019). Hedonic and eudaimonic motives toward university studies: how they relate to each other and to well-being derived from school. Journal of Positive School Psychology, 3(2), 179-196.

Center for Systems Science and Engineering. (2020). Coronavirus COVID-19 global cases at Johns Hopkins University. Available from https://coronavirus.jhu.edu/map.html.

Cohen, J. (1988). Statistical power analysis for the behavioral sciences (2nd ed.). Hillsdale: Lawrence Erlbaum.

Cohen, K., \& Cairns, D. (2011). Is searching for meaning in life associated with reduced subjective wellbeing? Confirmation and possible moderators. Journal of Happiness Studies, 13(2), 313-331. https://doi. org/10.1007/s10902-011-9265-7.

D’Agostino, R. B., Belanger, A., \& D’Agostino, R. B. (1990). A suggestion for using powerful and informative tests of normality. The American Statistician, 44(4), 316-321.

Dağl1, A., \& Baysal, N. (2016). Yașam Doyumu Ölçeğinin Türkçe’ye uyarlanması: Geçerlik ve güvenirlik çalıșması. Elektronik Sosyal Bilimler Dergisi, 15(59), 1250-1262. https://doi.org/10.17755/esosder.263229.

Damasio, B. F., de Melo, R. L. P., \& da Silva, J. P. (2013). Meaning in life, psychological well-being and quality of life in teachers. Paidéia (Ribeirão Preto), 23(54), 73-82. https://doi.org/10.1590/1982-43272354201309.

Demirci, İ., \& Ahmet, A. (2015). Ruh Sağlığı Sürekliliği Kısa Formu'nun geçerliği ve güvenirliği. Ankara Üniversitesi Eğitim Bilimleri Fakültesi Dergisi, 48(1), 49-64.

Derogatis, L. R., \& Fitzpatrick, M. (2004). The SCL-90-R, the Brief Symptom Inventory (BSI), and the BSI-18. In M. E. Maruish (Ed.), The use of psychological testing for treatment planning and outcomes assessment: instruments for adults (pp. 1-41). Mahwah: Lawrence Erlbaum Associates Publishers.

Diener, E., Emmons, R. A., Larsen, R. J., \& Griffin, S. (1985). The satisfaction with life scale. Journal of Personality Assessment, 49(1), 71-75.

Diener, E., Suh, E., Lucas, R., \& Smith, H. (1999). Subjective well-being: three decades of progress. Psychological Bulletin, 125(2), 276-302.

Diener, E., Wirtz, D., Tov, W., Kim-Prieto, C., Choi, D., Oishi, S., \& Biswas-Diener, R. (2010). New well-being measures: short scales to assess flourishing and positive and negative feelings. Social Indicators Research, 97(2), 143-156. https://doi.org/10.1007/s11205-009-9493-y.

Doğan, T., Sapmaz, F., Tel, F. D., Sapmaz, S., \& Temizel, S. (2012). Meaning in life and subjective well-being among Turkish university students. Procedia - Social and Behavioral Sciences, 55, 612-617. https://doi. org/10.1016/j.sbspro.2012.09.543.

Frankl, V. E. (1985). Man's search for meaning. New York: Simon and Schuster Publishers.

Galang, M. J. A., Magno, C., Paterno, V. C., \& Roldan, A. E. (2011). Meaning in life, flow and subjective wellbeing: a perspective on Filipino high school students. Journal of Counselling Psychology, 13(1), $29-45$.

García-Alandete, J. (2015). Does meaning in life predict psychological well-being? An analysis using the Spanish versions of the Purpose-In-Life Test and the Ryff's Scales. The European Journal of Counselling Psychology, 3(2), 89-98. https://doi.org/10.5964/ejcop.v3i2.27. 
García-Alandete, J., Martínez, E. R., Nohales, P. S., \& Lozano, B. Z. (2018). Meaning in life and psychological well-being in Spanish emerging adults. Acta Colombiana de Psicología, 21(1), 196-205. https://doi. org/10.14718/ACP.2018.21.1.9.

Garrosa-Hernández, E., Carmona-Cobo, I., Ladstätter, F., Blanco, L. M., \& Cooper-Thomas, H. D. (2013). The relationships between family-work interaction, job-related exhaustion, detachment, and meaning in life: a day-level study of emotional well-being. Revista de Psicología del Trabajo y de las Organizaciones, 29(3), 169-177. https://doi.org/10.5093/tr2013a23.

Gruber, J., \& Bekoff, M. (2017). A cross-species comparative approach to positive emotion disturbance. Emotion Review, 9, 72-78. https://doi.org/10.1177/1754073915615430.

Hedayati, M. A. M., \& Khazaei, M. A. M. (2014). An investigation of the relationship between depression, meaning in life and adult hope. Procedia - Social and Behavioral Sciences, 114, 598-601. https://oi. org/10.1016/j.sbspro.2013.12.753.

Hooper, D., Coughlan, J., \& Mullen, M. R. (2008). Structural equation modelling: guidelines for determining model fit. Electronic Journal of Business Research Methods, 6(1), 53-60.

Hu, L., \& Bentler, P. M. (1999). Cutoff criteria for fit indexes in covariance structure analysis: conventional criteria versus new alternatives. Structural Equation Modeling: A Multidisciplinary Journal, 6(1), 1-55.

Huang, H., \& Humphreys, B. R. (2012). Sports participation and happiness: evidence from US microdata. Journal of Economic Psychology, 33(4), 776-793 206-212. https://doi.org/10.1016/j.joep.2012.02.007.

Jeong, H., Yim, H. W., Song, Y. J., Ki, M., Min, J. A., Cho, J., \& Chae, J. H. (2016). Mental health status of people isolated due to Middle East respiratory syndrome. Epidemiology and Health, 38, e2016048. https://doi.org/10.4178/epih.e2016048.

Jim, H. S., \& Andersen, B. L. (2007). Meaning in life mediates the relationship between social and physical functioning and distress in cancer survivors. British Journal of Health Psychology, 12(3), 363-381. https://doi.org/10.1348/135910706X128278.

Kansky, J., \& Diener, E. (2017). Benefits of well-being: health, social relationships, work, and resilience. Journal of Positive School Psychology, 1(2), 129-169.

Keyes, C. L. (2002). The mental health continuum: From languishing to flourishing in life. Journal of Health and Social Behavior, 43, 207-222. https://doi.org/10.2307/3090197.

Keyes, C. L. M. (2005). Mental illness and/or mental health? Investigating axioms of the complete state model of health. Journal of Consulting and Clinical Psychology, 73, 539-548. https://doi.org/10.1037/0022-006 X.73.3.539.

Keyes, C. L. M. (2014). Mental health as a complete state: how the salutogenic perspective completes the picture. In G. F. Bauer \& O. Hämmig (Eds.), Bridging occupational, organizational and public health: a transdisciplinary approach (pp. 179-192). London: Springer.

Keyes, C. L. M., Shmotkin, D., \& Ryff, C. (2002). Optimizing well-being: the empirical encounter of two traditions. Journal of Personality and Social Psychology, 82, 1007-1022. https://doi.org/10.1037/00223514.82.6.1007.

Keyes, C. L. M., Wissing, M., Potgieter, J. P., Temane, M., Kruger, A., \& Van Rooy, S. (2008). Evaluation of the mental health continuum-short form (MHC-SF) in Setswana-speaking South Africans. Clinical Psychology \& Psychotherapy, 15(3), 181-192. https://doi.org/10.1002/cpp.572.

Kim, T., Lee, S. M., Yu, K., Lee, S., \& Puig, A. (2005). Hope and the meaning of life as influences on Korean adolescents' resilience: implications for counsellors. Asia Pasific Education Review, 6(2), $143-152$. https://doi.org/10.1007/BF03026782.

Kleftaras, G., \& Psarra, E. (2012). Meaning in life, psychological well-being and depressive symptomatology: a comparative study. Psychology, 3(04), 337-345.

Kline, R. B. (2015). Principles and practice of structural equation modeling. New York: Guilford.

Lin, C. Y. (2020). Social reaction toward the 2019 novel coronavirus (COVID-19). Social Health and Behavior, $3(1), 1-2$.

Lyubomirsky, S., King, L., \& Diener, E. (2005). The benefits of frequent positive affect: does happiness lead to success? Psychological Bulletin, 131, 803-855. https://doi.org/10.1037/0033-2909.131.6.803.

Maccallum, F., \& Bryant, R. A. (2019). A network approach to understanding quality of life impairments in prolonged grief disorder. Journal of Traumatic Stress, 33(1), 106-115. https://doi.org/10.1002/jts.22383.

Mascaro, N., \& Rosen, D. H. (2005). Existential meaning's role in the enhancement of hope and prevention of depressive symptoms. Journal of Personality, 73, 985-1013. https://doi.org/10.1111/j.14676494.2005.00336.x.

Mascaro, N., \& Rosen, D. H. (2008). Assessment of existential meaning and its longitudinal relations with depressive symptoms. Journal of Social and Clinical Psychology, 27, 576-599. https://doi.org/10.1521 /jscp.2008.27.6.576.

Moore, S., \& Diener, E. (2019). Types of subjective well-being and their associations with relationship outcomes. Journal of Positive School Psychology, 3(2), 112-118. 
Mulders, L. T. E. (2011). Meaning in life and its relationship to psychological well-being in adolescents. (Unpublished master thesis). Holland: Utrecht University.

Minkkinen, J., Auvinen, E., \& Mauno, S. (2020). Meaningful work protects teachers' self-rated health under stressors. Journal of PositiveSchool Psychology, 4(2), 140-152. https://doi.org/10.47602/jpsp.v4i2.209.

Peterson, C., \& Seligman, M. E. (2004). Character strengths and virtues. New York: Oxford University Press.

Petrillo, G., Capone, V., Caso, D., \& Keyes, C. L. M. (2015). The Mental Health Continuum-Short Form (MHC-SF) as a measure of well-being in the Italian context. Social Indicators Research, 121(1), 291-312. https://doi.org/10.1007/s11205-014-0629-3.

Qiu, J., Shen, B., Zhao, M., Wang, Z., Xie, B., \& Xu, Y. (2020). A nationwide survey of psychological distress among Chinese people in the COVID-19 epidemic: implications and policy recommendations. General Psychiatry, 33(2), e100213. https://doi.org/10.1136/gpsych-2020-100213.

Rosenberg, A. R. (2020). Cultivating deliberate resilience during the coronavirus disease 2019 pandemic. JAMA Pediatrics, 174, 817. https://doi.org/10.1001/jamapediatrics.2020.1436.

Ryan, R. M., \& Deci, E. L. (2001). On happiness and human potentials: a review of research on hedonic and eudaimonic well-being. Annual Review of Psychology, 52(1), 141-166.

Ryff, C. D., \& Keyes, C. L. M. (1995). The structure of psychological well-being revisited. Journal of Personality and Social Psychology, 69(4), 719-727.

Ryff, C. D., Magee, W. J., Kling, K. C., \& Wing, E. H. (1999). Forging macro-micro linkages in the study of psychological well-being. In C. D. Ryff \&V. M. Marshall (Eds.), The self and society in aging processes, (pp. 247-278). New York: Springer.

Santos, M. C. J., Magramo Jr., C., Oguan Jr., F., Paat, J. J., \& Barnachea, E. A. (2012). Meaning in life and subjective well-being: is a satisfying life meaningful? Journal of Arts, Science \& Commerce, 3(4-1), 32-40.

Seligman, M. E. P., \& Csikszentmihalyi, M. (2000). Positive psychology: an introduction. American Psychologist, 55, 5-14. https://doi.org/10.1037/0003-066X.55.1.5.

Sharf, R. S. (2012). Theories of psychotherapy \& counseling: concepts and cases. Ankara: Nobel yay.

Smith, N. D., Suldo, S., Hearon, B., \& Ferron, J. (2020). An application of the dual-factor model of mental health in elementary school children: examining academic engagement and social outcomes. Journal of Positive School Psychology, 4(1), 49-68.

Spiker, D. A., \& Hammer, J. H. (2019). Mental health literacy as theory: current challenges and future directions. Journal of Mental Health, 28(3), 238-242. https://doi.org/10.1080/09638237.2018.1437613.

Steger, M. F., Mann, J. R., Michels, P., \& Cooper, T. C. (2009). Meaning in life, anxiety, depression, and general health among smoking cessation patients. Journal of Psychosomatic Research, 67(4), 353-358. https://oi. org/10.1016/j.jpsychores.2009.02.006.

Tanhan, A. (2019). Acceptance and commitment therapy with ecological systems theory: addressing Muslim mental health issues and wellbeing. Journal of Positive School Psychology, 3(2), 197-219. https://oi. org/10.47602/jpsp.v3i2.172.

Tanhan, A. (2020). COVID-19 Sürecinde Online Seslifoto (OSF) yöntemiyle biyopsikososyal manevi ve ekonomik meseleleri ve genel iyi oluș düzeyini ele almak: OSF’nin Türkçeye uyarlanması. Electronic Turkish Studies, 15(4), 1029-1086. https://doi.org/10.7827/TurkishStudies.44451.

Tanhan, A., Yavuz, K. F., Young, J. S., Nalbant, A., Arslan, G., Yıldırım, M., et al. (2020). A proposed framework based on literature review of online contextual mental health services to enhance wellbeing and address psychopathology during COVID-19. Electronic Journal of General Medicine, 17(6), em254. https://doi.org/10.29333/ejgm/8316.

Telef, B. (2013). The Scale of Positive and Negative Experience: a validity and reliability study for adolescents. Anatolian Journal of Psychiatry, 14(1), 62-68.

Tian, F., Li, H., Tian, S., Yang, J., Shao, J., \& Tian, C. (2020). Psychological symptoms of ordinary Chinese citizens based on SCL-90 during the level emergency response to COVID-19. Psychiatry Research, 288, 112992. https://doi.org/10.1016/j.psychres.2020.112992.

Vickberg, S. M. J., Bovbjerg, D. H., DuHamel, K. N., Currie, V., \& Redd, W. H. (2000). Intrusive thoughts and psychological distress among breast cancer survivors: global meaning as a possible protective factor. Behavioral Medicine, 25(4), 152-160. https://doi.org/10.1080/08964280009595744.

Wang, L. Y., Chang, P. C., Shih, F. J., Sun, C. C., \& Jeng, C. (2006). Self-care behavior, hope, and social support in Taiwanese patients awaiting heart transplantation. Journal of Psychosomatic Research, 61(4), 485-491. https://doi.org/10.1016/j.jpsychores.2004.11.013.

Yıldırım, M., \& Arslan, G. (2020). Exploring the associations between resilience, dispositional hope, preventive behaviours, subjective well-being, and psychological health among adults during early stage of COVID-19. PsyArXiv. https://doi.org/10.31234/osf.io/vpu5q.

Yıldırım, M., \& Güler, A. (2020a). COVID-19 severity, self-efficacy, knowledge, preventive behaviors, and mental health in Turkey. Death Studies, 1-8. https://doi.org/10.1080/07481187.2020.1793434. 
Yıldırım, M., \& Güler, A. (2020b). Positivity explains how COVID-19 perceived risk increases death distress and reduces happiness. Personality and Individual Differences, 168, 110347. https://doi.org/10.1016/j. paid.2020.110347.

Yıldırım, M., Geçer, E., \& Akgül, Ö. (2020). The impacts of vulnerability, perceived risk, and fear on preventive behaviours against COVID-19. Psychology, Health \& Medicine, 1-9. https://doi.org/10.1080 /13548506.2020.1776891.

Zika, S., \& Chamberlain, K. (1992). On the relation between meaning in life and psychological well-being. British Journal of Psychology, 83, 133-145. https://doi.org/10.1111/j.2044-8295.1992.tb02429.x.

Publisher's Note Springer Nature remains neutral with regard to jurisdictional claims in published maps and institutional affiliations. 